\title{
Ectopic Thyroid Tissue in the Thyroglossal Cyst Duct: Rare Clinical Entity with Review of Literature
}

\author{
Sudhir M Naik, Rajshekar Halkud, SD Madhu, Purshottam Chavan, KT Siddappa, Sumit Gupta, KC Sunil \\ Samskruthi Moorthy, Prashanth Sinha, Jagdish Sarvadyna
}

\section{ABSTRACT}

The ectopic thyroid tissue is a rare developmental abnormality during embryogenesis where the thyroid gland passes from floor of the primitive foregut to its final pretracheal position. Its very important to verify the presence of a normally located normally functioning thyroid gland, thus excluding the possibility of an ectopic thyroid gland which resembles a TDC. A 12-year-old female presented to us with swelling in the midline of the neck region since 1 year. The mass moved with swallowing and protrusion of the tongue. On aspiration biopsy, a colloid material with cyst was confirmed. Imaging showed no orthotopic thyroid tissue on sonography and scintigraphy. No surgical intervention was done and as the patient was hypothyroid, levothyroxine replacement was given and the patient was advised for followup regularly. Hormonal estimation to rule out hypothyroid status and thyroid scintigraphy to detect the ectopic tissue and to see the presence of the normal orthotopic thyroid are essential investigations in evaluating thyroglossal cyst. Surgery is the treatment of choice in symptomatic lingual thyroids, with a role for radioiodine ablation in recurrent disease. Head and neck surgeons should evaluate ectopic thyroid as a differential diagnosis while evaluating mass in the midline as well as lateral neck.

Keywords: Ectopic thyroid tissue, Thyroglossal duct cyst, Hypothyroid, Orthotopic thyroid tissue, Scintigraphy.

How to cite this article: Naik SM, Halkud R, Madhu SD, Chavan P, Siddappa KT, Gupta S, Sunil KC, Moorthy S, Sinha P, Sarvadyna J. Ectopic Thyroid Tissue in the Thyroglossal Cyst Duct: Rare Clinical Entity with Review of Literature. World J Endoc Surg 2013;5(2):39-44.

Source of support: Nil

Conflict of interest: None

\section{INTRODUCTION}

Routine evaluation of the patient with radionucleotide scan should be the protocol before surgically managing a case of provisionally diagnosed thyroglossal cyst (TDC). ${ }^{1}$ Its very important to verify the presence of a normally located normally functioning thyroid gland, thus excluding the possibility of an ectopic thyroid gland which resembles a TDC. $^{2}$ The diagnosis of ectopic thyroid should be made before surgery as operating on case of ectopic thyroid will result in permanent hypothyroidism. ${ }^{2}$

The ectopic thyroid tissue is a rare developmental abnormality during embryogenesis where the thyroid gland passes from floor of the primitive foregut to its final pretracheal position. ${ }^{3,4}$ Seen in one in 1 lakh population nearly 440 cases have been reported where in 70 to $90 \%$ of cases as it is the only thyroid tissue present. ${ }^{3,4}$ Commonly seen in younger females but can be seen in age groups of 1 to 40 years. ${ }^{5,6}$

Thyroid follicular cells responsible for thyroxine production are derived from the thyroid anlage consisting of median and lateral anlages from the fourth branchial pouches. ${ }^{7}$ C-cells responsible for calcitonin production originate from the ultimobranchial bodies of the 4th pharyngeal pouch, located symmetrically on the side of the neck. ${ }^{7}$ At the 3rd or 4th week of intrauterine life endodermal diverticulum from the median plate of the floor of the pharyngeal gut descends in the midline, from the foramen cecum (located between the posterior $1 / 3$ and anterior $2 / 3$ of the tongue) to the final location of the gland, anteriorly to the pretrachea and larynx. ${ }^{7}$

By the 7th or 8th week of development, the thyroid reaches its normal position, the area below the thyroid cartilage, descending through the thyroglossal duct. ${ }^{8}$ Migration of the gland on 24th day, forms a narrow channel, thyroglossal duct which later atrophies. ${ }^{9,10}$ During the 10th week of fetal life, the duct is usually obliterated. Failure of obliteration may result in the development of a cystic dilatation at any time in life called as TDC. ${ }^{8}$ Ectopic thyroid tissue is the result of a failure of migration of thyroid, along the route of thyroglossal duct. ${ }^{11,12}$ High resolution ultrasonography of the neck usually is used to document the cyst and the normal orthotopic thyroid gland. ${ }^{2}$ We report a case of ectopic thyroid with hypothyroidism treated with hormone replacement therapy.

\section{CASE REPORT}

A 12-year-old female presented to us with swelling in the midline of the neck region since 1 year. The patient had no other complaints and she had no attained menarche. On examination, the patient had solitary swelling in the midline of the neck just above the level of the hyoid bone (Fig. 1). The swelling was firm nodular $4 \times 4 \mathrm{~cm}$ lesion, without signs of inflammation with intact skin on the surface. The patient had puffiness of the face and mild generalized edema of the lower limbs. As the swelling moved with deglutition and protrusion of the tongue, a provisional diagnosis of TDC, was done.

Fine needle aspiration biopsy revealed colloid material with cluster and sheets of cyst macrophages and a few benign thyroid follicular cells (Fig. 2). The features were suggestive of cystic lesion. Blood parameters were within normal limits but had a high alkaline phosphatase of the 
value of 269.0 U/l. X-ray soft tissue of the neck suggested a soft tissue opacity in front of the hyoid bone. Chest X-ray did not show any abnormality (Fig. 3).

Thyroid hormone estimation revealed T3 to be 122.9, T4 to be $6.52 \mathrm{Ugm} \%$, TSH to be $25.95 \mathrm{uIU} / \mathrm{ml}$ with frank TSH value elevation. On ultrasonography of the neck, normal thyroid gland was not visualized in the anatomical location. There is a well-defined heterogeneous hypoechoic lesions $1.9 \times 1.3 \mathrm{~cm}$ dimension with increased vascularity seen in the midline anterior and inferior to the body of the hyoid between the muscle attachments of the sternohyoid (Figs 4 and 5). Mildly enlarged lymph nodes are seen at bilateral levels, with rest of the soft tissues and the vessels being normal. A possible diagnosis of ectopic thyroid tissue was done with the thyroid scan confirming it.

Thyroid scan and uptake was carried out after intravenous administration of Tco4 pertechnetate. It revealed two areas of uniform circular areas of radiotracer distribution seen in the anterior side of the neck situated higher up than the normal anatomical position of the thyroid gland (Figs 6 and 7). The patient was hypothyroid and was treated with thyroid hormone supplementation and was advised regular 6 monthly follow-up.

\section{DISCUSSION}

Ectopic thyroid in $90 \%$ of the cases presents as a lingual thyroid at the base of the tongue embryologically the
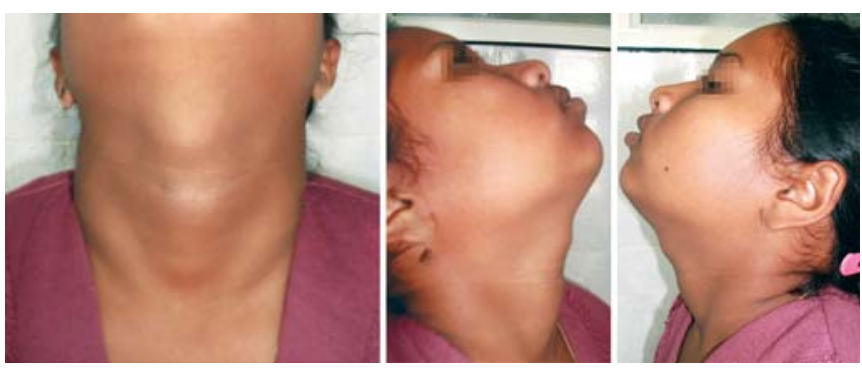

Fig. 1: Thyroglossal duct cyst seen in the suprahyoid area

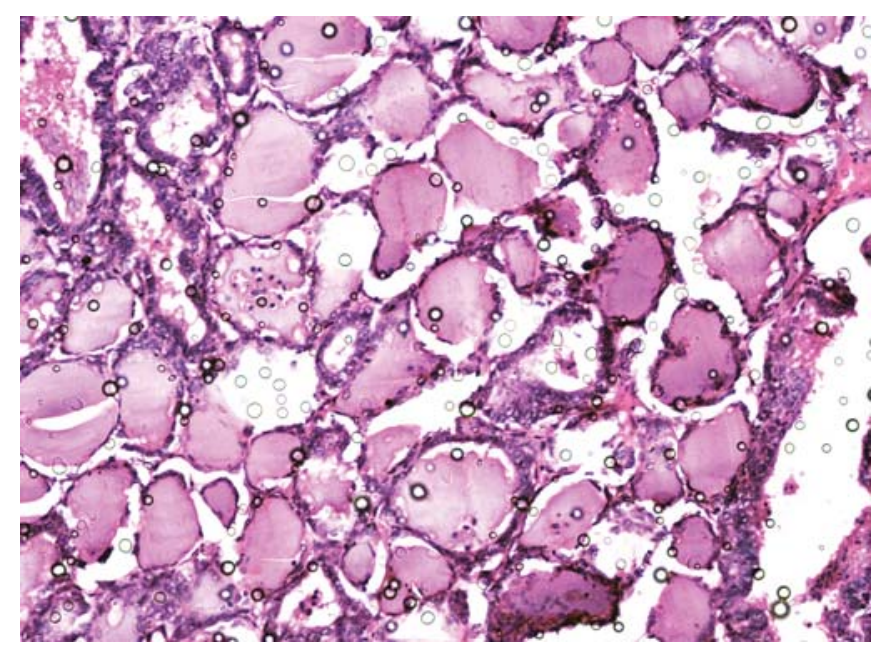

Fig. 2: Colloid material seen on fine needle aspiration biopsy foramen cecum. ${ }^{5,6}$ Patients range from 1 to 83 years with an average age of 40.5 years and its the only thyroid tissue in 70 to $75 \%$ of cases. ${ }^{13,14}$ The lingual thyroid manifests symptoms depending on the size as smaller ones are asymptomatic and discovered incidentally. ${ }^{15,16}$ Larger ones are present as dysphagia, dysphonia, stomatologia, foreign body sensation, cough and snoring. ${ }^{15,16}$ More severe cases can present as respiratory obstruction and hemorrhage. ${ }^{15,16}$ Most of them are hypothyroid unless an orthotopic thyroid is present where euthyroid status can be seen. ${ }^{15,16}$ Borderline hypothyroid status can be precipitated by medications interfering with iodine metabolism and actions of TSH, such as lithium and very rarely hyperthyroidism, is reported. ${ }^{13,16}$

The genetic mechanisms in defective thyroid organogenesis mainly include malfunctioning transcription factor TITF1/NKX2-1, which is responsible for the thyroidspecific expression of thyroglobulin (Tg), thyroperoxidase and the transcription factors PAX8, HHEX and FOXE1. ${ }^{2}$ They are expressed in functioning thyroid cells as well as their precursors and seem to be essential for the early stages of thyroid morphogenesis. ${ }^{9}$ TITF1/NKX2-1 controls the survival of the gland at early organogenesis as well as the expression of genes specific for thyroid follicular cells in adult life. ${ }^{9}$ PAX8 controls genetic regulatory cascade, which controls thyroid development required in survival of thyroid cell precursors and functional differentiation and FOXE1, is concerned with thyroid migration. ${ }^{9,17}$ So, thyroid dysgenesis may be due to mutations in these transcription factor genes. ${ }^{9}$ TSH receptor genes along with PAX8 are necessary for thyroid development and implicated in thyroid dysgenesis. $^{9}$

Ectopic thyroid is described at other sites between the base of the tongue and its final pretracheal position as well as in the mediastinum and distant subdiaphragmatic. ${ }^{2}$ Lateral ectopic thyroid gland in submandibular region is seen when the lateral anlage do not join the median anlage. ${ }^{7}$ They

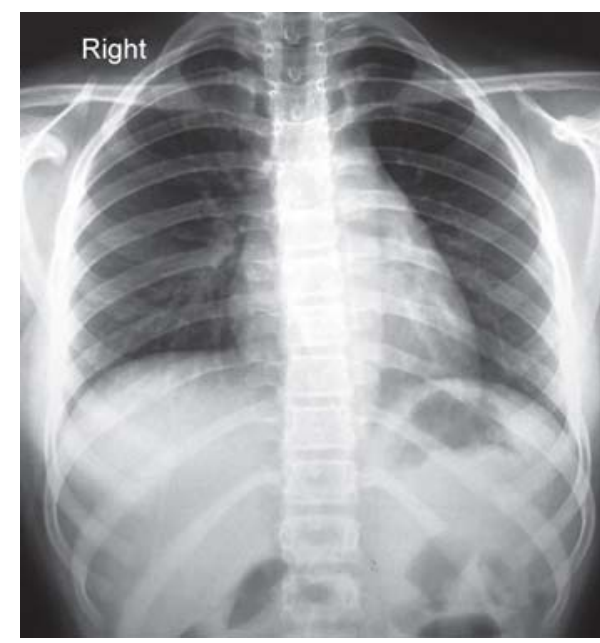

Fig. 3: Normal chest X-ray of the patient 
present as lateral, palpable, mobile, painless mass in the carotid triangle or the submandibular area commonly seen in females and usually located on the right side of the neck with euthyroid status. ${ }^{18,19}$ The etiology of these ectopy are displacement during the course of embryonic development, spread of tissue during surgery on an orthotopic thyroid gland and metastasis of a highly differentiated papillary thyroid carcinoma. ${ }^{18}$ Ectopic tissue may also be seen in the wall of thyroglossal duct, being asymptomatic with overall frequency of $5 \%{ }^{19}$
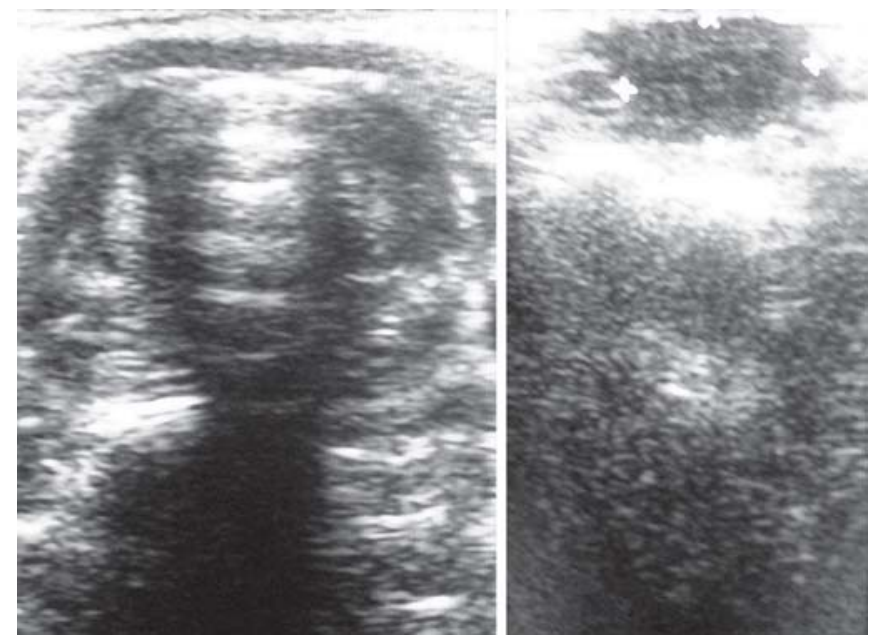

Fig. 4: Absence of normal orthotopic thyroid tissue in pre and paratracheal area
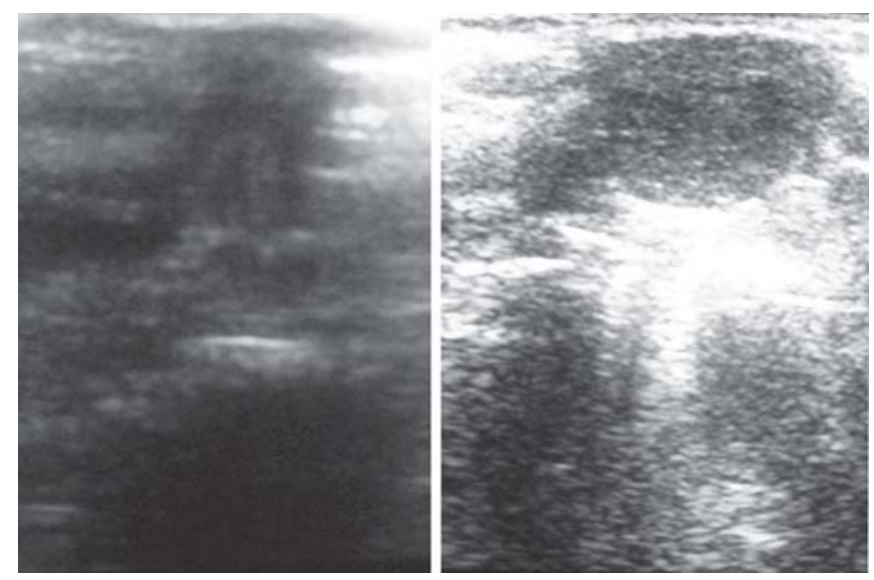

Fig. 5: Echostructure and dimensions of the cyst
The ectopic tissue is usually hypothyroid with changes of Hashimoto's thyroiditis and papillary carcinoma are reported. ${ }^{19}$ Other rare position of the ectopic thyroid tissue is its intratracheal position, seen commonly in females in the 4th and 5th decades presenting as cough, dysphagia, dyspnea, hemoptysis, stridor, rarely asymptomatic. ${ }^{20}$ Here, a euthyroid status is seen as the normal thyroid usually exists. ${ }^{21}$ Also rarely ectopic thyroid tissue can be seen in the intrathoracic region, i.e., mediastinum, lungs, and heart, manifesting usually with dry cough, dyspnea and hemoptysis. ${ }^{2}$ Here euthyroid status is seen in all cases as orthotopic thyroid gland coexists. ${ }^{22}$ More rarer locations are subdiaphragmatic, involving ovaries, adrenals, gallbladder, pancreas, duodenum and mesentery of the small intestine. ${ }^{2}$ In the ovaries, it develops as a teratoma containing a large amount of thyroid tissue, microscopically and biologically identical to normal thyroid called 'struma ovarii'.'

It may present as lower abdominal pain, palpable lower abdominal mass or abnormal vaginal bleeding or an incidental sonographic finding, with malignant transformation in $15 \%$ and hyperfunctioning thyroid in 5 to $15 \% .{ }^{23}$ Also rarely two ectopic foci one in the lingual or sublingual and the second is subhyoid, infrahyoid or suprahyoid may be present. ${ }^{24}$ In this instance, half of the patients are euthyroid and the rest are hypothyroid, usually with no radionuclide uptake in the region of normal thyroid gland. ${ }^{24}$

Primary thyroid carcinomas arising from ectopic thyroid tissue are very rare and reported in lingual thyroid, thyroglossal duct cyst, lateral aberrant thyroid tissue, mediastinal and struma ovarii diagnosed postoperatively. ${ }^{25}$ Commonly, found are papillary carcinomas, while follicular, Hurthle cell and medullary carcinomas are also reported. ${ }^{25}$ Primary carcinoma in ectopic thyroid may occur in presence of normal orthotopic thyroid or from the ectopic with no orthotopic thyroid. ${ }^{25}$ Here, differentiating between carcinoma arising in ectopic thyroid tissue and a metastatic carcinoma is difficult. ${ }^{25}$ Imaging of the separate blood supply to the ectopic gland from extracervical vessels and

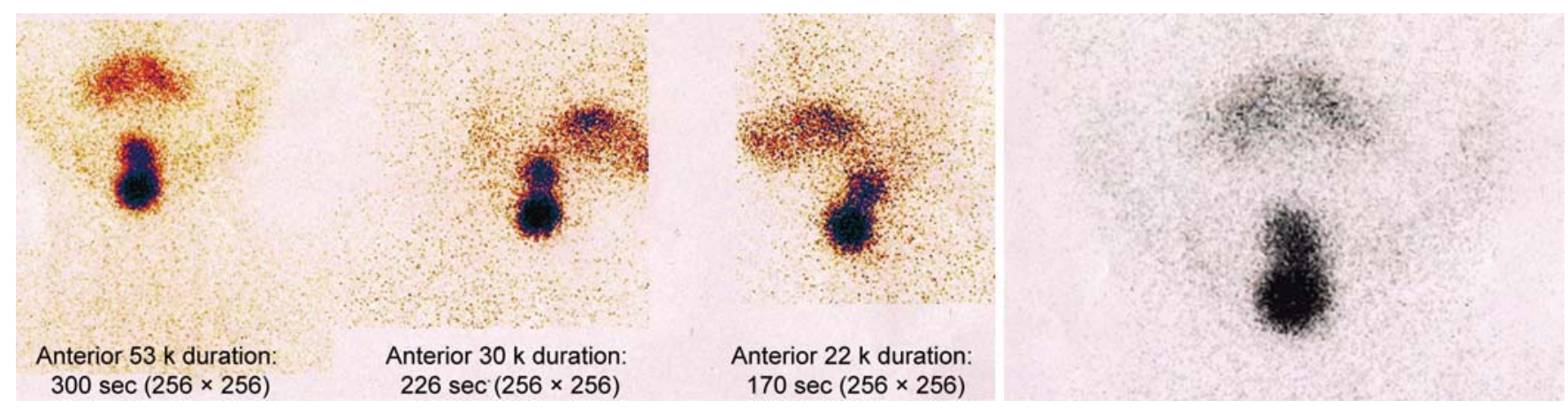

Fig. 6: Thyroid scintigraphy solitary uptake at the cyst and the lingual aspect 


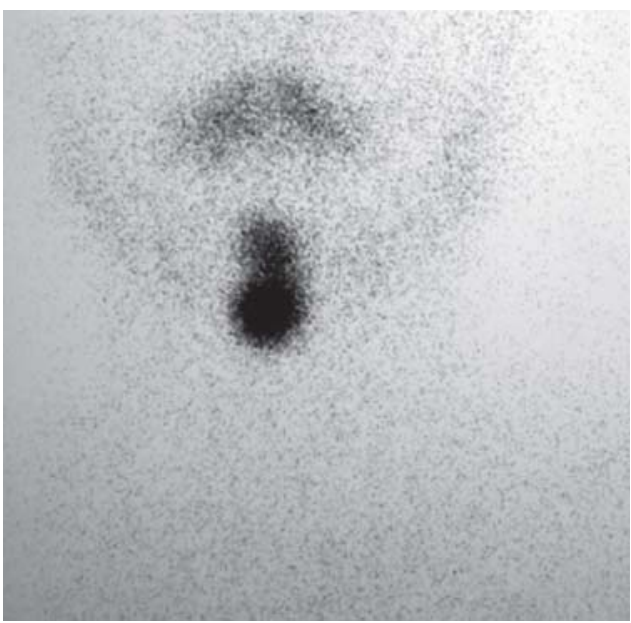

Fig. 7: Absent orthotopic thyroid confirmed of scintigraphy

the normal orthotopic thyroid tissue helps to differentiate the site of origin of the malignancy. ${ }^{25}$

Thyroid scintigraphy using Tc-99m, I-131 or I-123 confirms the ectopic thyroid tissue and shows the absence or presence of thyroid in its normal location. ${ }^{2}$ It is both sensitive and specific for differentiation of an ectopic thyroid from other causes of midline neck masses with false positives due to normal or uptake in the head and neck. ${ }^{6,7}$ Physiologically, uptakes can also be seen in nasal mucosa, salivary glands, intestine, liver and urinary bladder, while causes of pathological uptake may be meningiomas, dacryocystitis, sinusitis, prosthetic eye and dental disease. ${ }^{26}$ Pinczower et al, in 1992, indicated that $28 \%$ of pediatric surgeons and $60 \%$ of pediatric otolaryngologists routinely obtain preoperative radionuclide thyroid scans before managing TDCs. ${ }^{1}$

Doppler sonography computed tomography (CT) and magnetic resonance imaging (MRI) help in defining the extent and location of ectopic tissue in preoperative evaluation. ${ }^{7}$ Color Doppler sonography has better sensitivity of $90 \%$ in detecting ectopic thyroid in patients with congenital hypothyroidism, the color signal corresponded precisely to the focal concentration as indicated by radionuclide imaging. ${ }^{27}$ It appeared to be either hypoechoic or hyperechoic compared with the surrounding tissue. ${ }^{27}$

CT and MRI are accurate in identifying the site of ectopy when radioiodine uptake by normal thyroid gland masks the uptake of the ectopic thyroid tissue, especially in the midline. ${ }^{28}$ Contrast-enhanced images identify thyroid tissue more clearly while on MRI ectopic thyroid appears as a rounded mass with higher signal intensity than that of the surrounding tissue in both the T1- and T2-weighed images. ${ }^{16}$ Confirmation of the ectopic is done by fine needle aspiration cytology (FNAC) which also differentiates it between a benign and a malignant lesion. ${ }^{6,7}$ Repeat aspiration cytologies may be needed as it may be misleading or nondiagnostic, especially in cystic masses. ${ }^{16}$

In adults, metastasis should be excluded as they manifest as ectopic tissues. ${ }^{26}$ Lingual and submandibular thyroid must be differentiated from midline adenomas and cysts, including angiomas, fibromas, lymphangiomas, lipomas, salivary gland tumors, thyroglossal duct cysts, midline branchial cysts and sebaceous cysts. ${ }^{3,15}$

Lingual thyroid must also be differentiated from base of the tongue lesions like hypertrophic lingual tonsil, vallecular cyst and mucous retention cyst. ${ }^{24}$ Surgical management depends on the size of the mass, functional thyroid status, local symptoms like airway obstruction, dysphagia and dysphonia. ${ }^{7,15,16}$ The surgical indication becomes absolute when complications of the mass like ulceration, bleeding, cystic degeneration or malignancy is seen. ${ }^{7,15,16}$

Asymptomatic and euthyroid ectopics needs regular follow-up to detect complications but some recommend complete surgical resection fearing malignant transformation. ${ }^{15,25}$ Levothyroxine replacement therapy is effective for mild symptoms and hypothyroid condition which will shrink the mass effect considerably. ${ }^{15,25}$ Transoral resection of the lingual thyroid is the preferred surgical approach, while transhyoid, suprahyoid or lateral pharyngotomy is also used. $^{2}$ Transoral is preferred for small lesions since and complications, such as lingual nerve injury and deep cervical infections, are avoided. ${ }^{2}$

The latter approach with or without preoperative tracheotomy is chosen for larger masses providing better control of bleeding and exposure. ${ }^{10,15}$ The success of transoral techniques are supplemented by monopolar coagulation, the $\mathrm{CO}_{2}$ or diode laser. ${ }^{10,15}$ Accidental removal of the only present thyroid tissue needs reimplantation of the ectopic to avoid permanent hypothyroidism. ${ }^{10,15}$ In symptomatic cases, where surgery is contraindicated suppressive hormone therapy with levothyroxine in order to avoid ectopic thyroid tissue growth and I-131 therapy for decreasing tumor's size can be proposed. ${ }^{16}$

Managing ectopic thyroid in the sublingual, submandibular and lateral cervical depends on size of the lesion, symptoms, age, thyroid status and complications of the lesion like ulceration, bleeding and malignancy. ${ }^{29}$ Kiran et al reported that subhyoid ectopic thyroid tissues without orthotopic thyroid tissues can be vertically split and placed with its vascularity below the strap muscles laterally. ${ }^{30}$

Iodine ablation of lingual thyroid appears to be a safe and effective strategy resulting in complete resolution of symptoms, 2 months after treatment and no disease recurrence during follow-up is seen. ${ }^{31}$ Higher doses of 
radioiodine may be required for size reduction than those required to ablate the thyroid bed tissue. ${ }^{13}$ In children and young adults, radioiodine ablation is contraindicated as it damages the gonads and other organs. ${ }^{15}$

\section{CONCLUSION}

Ectopic thyroid tissue develops earlier as developmental defects in embryogenesis and most of the cases are asymptomatic. Hormonal estimation to rule out hypothyroid status and thyroid scintigraphy to detect the ectopic and to see the presence of the normal orthotopic thyroid are essential investigations.

Surgery is the treatment of choice in symptomatic cases, with a role for radioiodine ablation in recurrent disease. Head and neck surgeons should evaluate this as a differential diagnosis while evaluating mass in the midline as well as lateral neck.

\section{REFERENCES}

1. Pinczower E, Crockett DM, Atkinson JB, Kun S. Preoperative thyroid scanning in presumed thyroglossal duct cysts. Arch Otolaryngol Head Neck Surg 1992;118:985-88.

2. Lim-Dunham JE, Feinstein KA, Yousefzadeh DK, Ben-Ami T. Sonographic demonstration of a normal thyroid gland excludes ectopic thyroid in patients with thyroglossal duct cyst. AJR Am J Roentgenol 1995 Jun;164(6):1489-91.

3. Di Benedetto V. Ectopic thyroid gland in the submandibular region simulating a thyroglossal duct cyst: A case report. J Pediatr Surg 1997;32:1745-46.

4. Babazade F, Mortazavi H, Jalalian H, Shahvali E. Thyroid tissue as a submandibular mass: A case report. J Oral Sci 2009;51: 655-57.

5. Gopal RA, Acharya SV, Bandgar T, Menon PS, Marfatia H, Shah NS. Clinical profile of ectopic thyroid in Asian Indians: A single-center experience. Endocr Pract 2009;15:322-25.

6. Yoon JS, Won KC, Cho IH, Lee JT, Lee HW. Clinical characteristics of ectopic thyroid in Korea. Thyroid 2007;17:1117-21.

7. Bersaneti JA, Silva RD, Ramos RR, Matsushita Mde M, Souto LR. Ectopic thyroid presenting as a submandibular mass. Head Neck Pathol 2011;5:63-66.

8. Naik SM, Naik SS. An overview of 22 thyroglossal cysts managed in KVG medical college. Int J Head Neck Surg 2011 Jan-April;2(1):5-9.

9. De Felice M, Lauro R. Thyroid development and its disorders: Genetics and molecular mechanisms. Endocr Rev 2004;25: 722-46.

10. Gallo A, Leonetti F, Torri E, Manciocco V, Simonelli M, DeVincentiis M. Ectopic lingual thyroid as unusual cause of severe dysphagia. Dysphagia 2001;16:220-23.

11. Cassol CA, Noria D, Asa SL. Ectopic thyroid tissue within the gall bladder: Case report and brief review of the literature. Endoc Pathol 2010;21:263-65.

12. Shuno Y, Kobayashi T, Morita K, Shimizu S, Nishio Y, Ito A, et al. Ectopic thyroid in the adrenal gland presenting as cystic lesion. Surgery 2006;139:580-82.

13. Neinas FW, Gorman CA, Devine KD, Woolner LB. Lingual thyroid. Clinical characteristics of 15 cases. Ann Intern Med 1973;79:205-10.
14. Batsakis JG, El-Naggar AK, Luna MA. Thyroid gland ectopias. Ann Otol Rhinol Laryngol 1996;105:996-1000.

15. Toso A, Colombani F, Averono G, Aluffi P, Pia F. Lingual thyroid causing dysphagia and dyspnoea. Case reports and review of the literature. Acta Otorhinolaryngol Ital 2009;29:213-17.

16. Talwar N, Mohan S, Ravi B, Andley M, Kumar A. Lithium induced enlargement of a lingual thyroid. Singapore Med J 2008;49:254-55.

17. Pasca di Magliano M, Di Lauro R, Zannini MS. Pax8 has a key role in thyroid cell differentiation. PNAS 2000;97:13144-49.

18. Feller KU, Mavros A, Gaertner HJ. Ectopic submandibular thyroid tissue with a coexisting active and normally located thyroid gland: Case report and review of literature. Oral Surg Oral Med Oral Pathol Oral Radiol Endodont 2000;90: 618-23.

19. Maino K, Skelton H, Yeager J, Smith KJ. Benign ectopic thyroid tissue in a cutaneous location: A case report and review. J Cutan Pathol 2004;31:195-98.

20. Rao PN, Pandit N, Kumar R, Upadhya IV, Vidya Sagar MS. Ectopic functioning thyroid tissue in the thyroglossal duct detected by radionuclide imaging. Clin Nucl Med 2005; 30:630.

21. Muysoms F, Boedts M, Claeys D. Intratracheal ectopic thyroid tissue mass. Chest 1997;112:1684-85.

22. Richmond I, Whittaker JS, Deiraniya AK, Hassan R. Intracardiac ectopic thyroid: A case report and review of published cases. Thorax 1990;45:293-94.

23. Yoo SC, Chang KH, Lyu MO, Chang SJ, Ryu HS, Kim HS. Clinical characteristics of struma ovarii. J Gynecol Oncol 2008;19:135-38.

24. Chawla M, Kumar R, Malhotra A. Dual ectopic thyroid: Case series and review of the literature. Clin Nucl Med 2007;32:1-5.

25. Shah BC, Ravichand CS, Juluri S, Agarwal A, Pramesh CS, Mistry RC. Ectopic thyroid cancer. Ann Thorac Cardiovasc Surg 2007;13:122-24.

26. Basaria S, Westra WH, Cooper DS. Ectopic lingual thyroid masquerading as thyroid cancer metastases. J Clin Endocrinol Metab 2001;86:392-95.

27. Ohnishi H, Sato H, Noda H, Inomata H, Sasaki N. Color Doppler ultrasonography: Diagnosis of ectopic thyroid gland in patients with congenital hypothyroidism caused by thyroid dysgenesis. J Clin Endocrinol Metab 2003;88:5145-49.

28. Yang Y, Li Q, Qu J, Xiang Y, Pan Y, Liao Z, et al. Ectopic intratracheal thyroid. Southern Med J 2010;103:467-70.

29. Datta RV, Petrelli NJ, Ramzy J. Evaluation and management of incidentally discovered thyroid nodules. Surg Oncol 2006;15(1): 33-42.

30. Naik KM. Redefining anatomy in a of midline subhyoid ectopic thyroid. Int J Head And Neck Surg 2012;3(3):179-81.

31. Iglesias P, Olmos-García R, Riva B, Díez JJ. Iodine 131 and lingual thyroid. J Clin Endocrinol Metab 2008;93:4198-99.

\section{ABOUT THE AUTHORS}

\section{Sudhir M Naik (Corresponding Author)}

Fellow, Department of Head and Neck Oncosurgery, Kidwai Institute of Oncology, Bengaluru, Karnataka, India, e-mail: sud223m@gmail.com

\section{Rajshekar Halkud}

Associate Professor, Department of Head and Neck Oncosurgery Kidwai Institute of Oncology, Bengaluru, Karnataka, India 


\section{SD Madhu}

Assistant Professor, Department of Radiodiagnosis, Kidwai Memorial Institute of Oncology, Bengaluru, Karnataka, India

\section{Purshottam Chavan}

Associate Professor, Department of Head and Neck Oncology, Kidwai Memorial Institute of Oncology, Bengaluru, Karnataka, India

\section{KT Siddappa}

Assistant Professor, Department of Head and Neck Oncology, Kidwai Memorial Institute of Oncology, Bengaluru, Karnataka, India

\section{Sumit Gupta}

Fellow, Department of Head and Neck Oncology, Kidwai Memorial Institute of Oncology, Bengaluru, Karnataka, India

\section{KC Sunil}

Fellow, Department of Head and Neck Oncology, Kidwai Memorial Institute of Oncology, Bengaluru, Karnataka, India

\section{Samskruthi Moorthy}

Fellow, Department of Head and Neck Oncology, Kidwai Memorial Institute of Oncology, Bengaluru, Karnataka, India

\section{Prashanth Sinha}

Senior Resident, Department of Radiodiagnosis, Kidwai Memorial Institute of Oncology, Bengaluru, Karnataka, India

\section{Jagdish Sarvadyna}

Fellow, Department of Oral Oncology, Kidwai Memorial Institute of Oncology, Bengaluru, Karnataka, India 